\title{
RELAÇÕES HÍDRICAS E TROCAS GASOSAS NA SELEÇÃO PRECOCE DE CLONES DE EUCALIPTO PARA AMBIENTES COM DIFERENCIADA DISPONIBILIDADE DE ÁGUA NO SOLO
}

\author{
Sandro Dan Tatagiba*, José Eduardo Macedo Pezzopane**, Edvaldo Fialho dos Reis*** \\ *Eng. Agrônomo, M.Sc. - Plantar Florestamento - sandro-tatagiba@plantar.com.br \\ **Eng. Florestal, Dr., Dep. Engenharia Florestal, UFES (CCA) - jemp@ufes.br \\ ***Eng. Agrícola, Dr., Dep. Engenharia Rural, UFES (CCA) - edreis@ufes.br \\ Recebido para publicação: 03/04/2007 - Aceito para publicação: 19/09/2007
}

\begin{abstract}
Resumo
Este estudo teve como objetivo avaliar as respostas das relações hídricas e das trocas gasosas em quatro clones de eucalipto $(97,11,75,84)$, estabelecidos em vasos plásticos, de modo a subsidiar a seleção precoce desses materiais genéticos para o estabelecimento em áreas com diferenciada disponibilidade de água no solo. As plantas cresceram em vasos, com teor de água próximo à capacidade de campo, durante um período de 150 dias, sendo, em seguida, iniciados os manejos hídricos diferenciados, mantidos até o final do experimento, que durou cerca de 250 dias. O déficit hídrico promoveu redução nos valores de fotossíntese, condutância estomática, transpiração, eficiência no uso da água e potencial hídrico foliar dos clones no final do experimento. O clone 11 apresentou o menor valor de fotossíntese, condutância estomática e transpiração quando submetido à deficiência hídrica. Os clones 97 e 75 apresentaram os maiores valores de fotossíntese e potencial hídrico foliar nas plantas submetidas ao déficit hídrico, evidenciando serem os mais indicados para plantio em áreas com elevada deficiência hídrica no solo.
\end{abstract}

Palavras-chave: Potencial hídrico foliar; manejos hídricos; fotossíntese.

\begin{abstract}
Water relations and gaseous changes in the precocious selection of Eucalyptus clones for environments with varying soil water availability. This study had as objective to evaluate the answers of the water relations and of the gaseous changes in four eucalyptus clones $(97,11,75,84)$, established in plastic vases, in way to subsidize the precocious selection of this genetic materials for the establishment in areas with varying soil water availability. Plants grew in vases, with water content at field capacity, during a period of 150 days, after that until the end of the experiment that lasted about 250 day, soil water regime was diversed. Water deficit regimes promoted reduction in the photosynthesis values, stomatal conductance, transpiration, efficiency in the use of the water and leaf water potential of the clones in the end of the experiment. Clone 11 presented the smallest photosynthesis value, stomatal conductance and transpiration when submitted to the water deficiency. The clones 97 and 75 presented the largest photosynthesis values and leaf water potential, in plants submitted to the alternated water regime of irrigation and deficit, showing to be the most suitable for planting in areas with high soil water deficiency.

Keywords: Leaf water potential; soil water management; photosynthesis.
\end{abstract}

\section{INTRODUÇÃO}

A seleção de material genético de eucalipto é de interesse em áreas com acentuada variação da disponibilidade de água no solo, podendo ser de fundamental importância para o êxito de um povoamento florestal. A identificação desses genótipos para implantação em condições ambientais adversas, especialmente em relação à deficiência hídrica no solo, é um desafio para muitas empresas florestais.

Os testes de espécies e procedências e os testes clonais têm sido usados para recomendar material genético para condições ambientais específicas (FRAMPTON; FOSTER, 1993). Alguns trabalhos com mudas de eucalipto têm sido desenvolvidos sob diferentes condições de disponibilidade 
hídrica no solo para indicar clones mais adequados às condições hídricas prevalecentes em uma determinada região (FAÇANHA, 1983; LI, 1998; GONÇALVES; PASSOS, 2000; CHAVES et al., 2004). Chaves et al. (2004) observaram variações nas respostas de clones de Eucalyptus mantidas sob diferentes condições de disponibilidade hídrica, em tubetes, indicando os genótipos as áreas com diferenciada disponibilidade de água no solo. Lima et al. (2003), por sua vez, analisaram as trocas gasosas em cinco espécies de Eucalyptus (E. grandis, E. urophyla, E. camaldulenses, E. torelliana e E. pharotrica), submetidas ao aumento na concentração de $\mathrm{CO}_{2}$ e a interação com o estresse hídrico em vasos, e observaram que as taxas de fotossíntese, condutância estomática e transpiração foram menores em todas as plantas submetidas ao déficit hídrico, quando comparadas com as taxas das mesmas plantas irrigadas. O efeito do estresse hídrico no fechamento dos estômatos foi similar em ambas as concentrações de $\mathrm{CO}_{2}$ utilizadas, embora os efeitos positivos do aumento da concentração de $\mathrm{CO}_{2}$ dentro da câmara sobre a fotossíntese e a eficiência do uso de água se manteve por um período comparativamente mais longo.

Dessa forma, objetivou-se neste trabalho estudar as respostas das relações hídricas e das trocas gasosas em quatro clones de eucalipto submetidos a três diferentes manejos de irrigação, a fim de promover a seleção precoce desses clones para áreas com diferenciada disponibilidade hídrica no solo.

\section{MATERIAL E MÉTODOS}

\section{Local, material experimental e substrato}

O experimento foi realizado no período de fevereiro a outubro de 2005, na área experimental do Núcleo de Estudos e Difusão de Tecnologia em Florestas, Recursos Hídricos e Agricultura Sustentável (NEDTEC), do Centro de Ciências Agrárias da Universidade Federal do Espírito Santo (CCA-UFES), localizado no município de Jerônimo Monteiro, situado na latitude $20^{\circ} 47^{\prime} 25^{\prime \prime} \mathrm{S}$ e longitude $41^{\circ} 23^{\prime} 48^{\prime \prime} \mathrm{W}$, à altitude de $120 \mathrm{~m}$.

Foram utilizadas mudas de quatro clones comerciais de eucalipto produzidas pela Aracruz Celulose S/A. As mudas foram produzidas em tubetes plásticos de aproximadamente $54 \mathrm{~mL}$ pelo método da estaquia e mantidas no viveiro até os 90 dias de idade. Após esse período, as mudas passaram por uma seleção quanto à uniformidade e foram transplantadas em vasos de $42 \mathrm{~cm}$ de diâmetro e $72 \mathrm{~cm}$ de altura, com capacidade de $100 \mathrm{dm}^{3}$. Esses vasos apresentavam furos circulares de $5 \mathrm{~cm}$ de diâmetro em suas faces laterais, a fim de permitir melhor aeração das raízes e escoar o excesso de água.

As mudas cresceram nos vasos mantidos com teor de umidade próximo à capacidade de campo, definida como a máxima retenção de água no substrato depois que o excesso tenha sido drenado (BERNARDO et al., 2005), por um período de 150 dias, quando, então, foram iniciados os manejos de irrigação diferenciados até o final do experimento, que durou cerca de 250 dias. Nesse período, os vasos foram vedados com lona plástica preta e fita adesiva, a fim de se evitar a entrada de água e possibilitar a indução do déficit hídrico, já que o experimento foi montado a céu aberto. Os manejos hídricos aplicados foram:

a) Irrigado: manutenção dos vasos com umidade do solo próxima à capacidade de campo ao longo de todo o período experimental.

b) Retomada da irrigação: suspensão da irrigação aos 150 dias de experimentação, durante 45 dias, e posterior retomada da irrigação por mais 55 dias no nível da capacidade de campo.

c) Déficit: suspensão da irrigação aos 150 dias de experimentação, prolongando até o final do experimento (100 dias de déficit hídrico).

A irrigação dos vasos foi realizada a partir da instalação de um sistema de irrigação por gotejamento, utilizando-se dois gotejadores autocompensantes por vaso, com vazão de 4,5 L.h ${ }^{-1}$. No início do experimento, os vasos foram submetidos à saturação por água durante 3 dias consecutivos, durante 6 horas por dia, e logo depois à drenagem livre, por um período de 24 horas, até o total cessamento e estabilização da umidade volumétrica na capacidade de campo, quando foi feito o transplantio das mudas.

O monitoramento do teor de umidade do substrato nos vasos sem déficit hídrico foi realizado por sensores acoplados a datalogger, modelo CS616, da Campbell Scientific, e com método termogravimétrico (EMBRAPA, 1997), a partir da coleta de amostras a $30 \mathrm{~cm}$ de profundidade. A calibração dos sensores foi realizada por meio de leituras simultâneas do teor de umidade do substrato, 
tomando-se o método termogravimétrico como padrão. Já nos vasos sob déficit hídrico, o monitoramento da umidade do substrato foi realizado pelo método termogravimétrico, devido à imprecisão dos sensores a teores de umidade inferiores a $18 \%$.

Para obtenção das variáveis microclimáticas, foi instalada uma estação meteorológica automática, modelo CR 10, que possibilitou o armazenamento e o processamento dos dados no sistema de coleta (datalogger). A estação estava equipada com um piranômetro e sensores de temperatura e umidade relativa do ar.

O déficit de pressão de vapor do $\operatorname{ar}(\Delta \mathrm{e})$ foi calculado pela diferença entre a pressão de saturação de vapor d'água $\left(\mathrm{e}_{\mathrm{s}}\right)$ e a pressão parcial de vapor $\left(\mathrm{e}_{\mathrm{a}}\right)$ (PEREIRA et al., 2002), conforme equação 1:

$$
\Delta \mathrm{e}=\mathrm{e}_{\mathrm{s}}-\mathrm{e}_{\mathrm{a}}
$$

A pressão de saturação de vapor $\left(\mathrm{e}_{\mathrm{s}}\right)$ foi calculada aplicando-se a equação 2 , de Tetens: $\mathrm{e}_{\mathrm{s}}=0,610810^{7,5 \mathrm{Tar} / 237,3+\mathrm{Tar}}$

em que Tar é a temperatura do ar, em ${ }^{\circ} \mathrm{C}$, e es é expressa em $\mathrm{kPa}$.

A pressão parcial de vapor (ea), por sua vez, foi calculada pela equação 3 :

$$
\mathrm{e}_{\mathrm{a}}=\mathrm{UR} \% . \mathrm{e}_{\mathrm{s}} / 100
$$

em que UR é a umidade relativa atual do ar, em \%.

O substrato utilizado para o enchimento dos vasos foi constituído de solo extraído à profundidade de 40 a $80 \mathrm{~cm}$ de um Latossolo Vermelho-Amarelo (55\%), areia lavada (30\%) e composto de casca bioestabilizada de eucalipto (15\%). Foi realizada análise granulométrica do substrato, obtendo-se a classificação textural como franco-arenoso.

A necessidade da aplicação de corretivos e de adubos químicos foi feita com base na análise química do substrato. No plantio, não foi necessário fazer adubação e correção da acidez do solo. Durante o período experimental, foram realizadas três adubações de cobertura, conforme recomendação de Silveira et al. (2001), sendo a primeira realizada a partir dos 45 dias após o transplantio. As demais adubações seguiram o mesmo período de tempo, realizadas a cada 45 dias. Essas adubações foram realizadas de modo a fornecer $1,20 \mathrm{mg}$ de nitrogênio e $1,25 \mathrm{mg}$ de potássio para cada vaso na primeira aplicação, e nas demais, $1,80 \mathrm{mg}$ de nitrogênio e $2,0 \mathrm{mg}$ de potássio, aplicadas na forma de uréia e cloreto de potássio. Os adubos foram diluídos em frasco contendo $100 \mathrm{~mL}$ de água e aplicados em cada vaso, inclusive nos submetidos ao manejo de déficit hídrico.

A curva de retenção de água do substrato, por secamento foi determinada conforme Embrapa (1997), a partir de amostras deformadas, previamente peneiradas, que, depois de saturadas por, no mínimo, 12 horas, foram levadas à câmara de pressão de Richards com placa porosa, para estabilização, adotando-se um tempo não inferior a três dias, e posterior determinação da umidade gravimétrica (U), correspondente às tensões de 0,$006 ; 0,010 ; 0,033 ; 0,08 ; 0,10 ; 0,30 ; 0,8$ e $1,5 \mathrm{MPa}$, com três repetições. A umidade volumétrica $(\theta)$ para cada uma das tensões foi obtida pelo produto da umidade gravimétrica pela densidade do solo $(\theta=$ U.Ds). Os valores médios de umidade volumétrica na curva de retenção do substrato foram ajustados utilizando-se o modelo matemático proposto por Van Genuchten (1980), conforme pode ser observado na figura 1 .

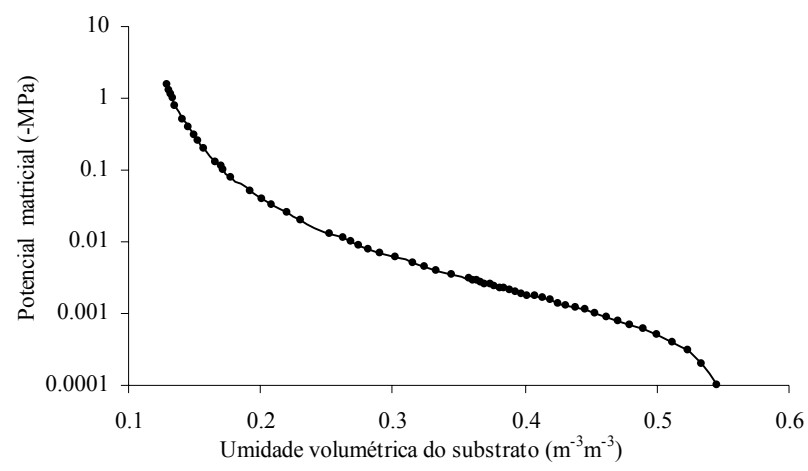

Figura 1. Curva de retenção de água no substrato.

Figure 1. Curve of water content in the substratum. 


\section{Água disponível e lâmina de irrigação}

A água disponível (AD) encontrada foi de 17,3\%, calculada observando-se os valores de umidade volumétrica na curva de retenção do substrato para a capacidade de campo (CC) em 30,2\% determinada na tensão de $0,006 \mathrm{MPa}$, e para o ponto de murcha permanente (PMP) em 12,9\% na tensão de 1,5 MPa, utilizando-se a equação 4 (CENTURION; ANDREOLI, 2000):

$$
\mathrm{AD}=\mathrm{CC}-\mathrm{PMP}
$$

A lâmina de irrigação (L) para os vasos sem déficit hídrico, ou seja, a umidade do substrato mantida próxima à capacidade de campo, foi calculada pela equação 5 (SOUSA et al., 2003):

$$
\mathrm{L}=\left[\left(\mathrm{CC}-\mathrm{U}_{\mathrm{a}}\right) / 10\right] \times \text { Ds } \times \mathrm{Z}
$$

sendo $\mathrm{L}$ a lâmina de irrigação (em mm), $\mathrm{CC}$ a umidade na capacidade de campo (\% em peso), $\mathrm{U}_{\mathrm{a}}$ a umidade atual do substrato (\% em peso estabelecido em $27,2 \%$ para reinício das irrigações), Ds a densidade do substrato $\left(\mathrm{em} \mathrm{g.cm}{ }^{-3}\right) \mathrm{e} \mathrm{Z}$ a profundidade do sistema radicular $(\mathrm{em} \mathrm{cm})$. Para transformar a lâmina de irrigação (L) em volume (L/vaso), multiplicou-se L pela área do vaso $\left(0,139 \mathrm{~m}^{2}\right)$. A densidade do substrato (Ds) foi realizada pelo método da proveta, conforme Embrapa (1997), obtendo-se o valor de 1,18 g. $\mathrm{cm}^{-3}$.

As lâminas de irrigação aplicadas foram estabelecidas no tempo, de acordo com crescimento da planta e pelo acompanhamento do desenvolvimento do sistema radicular, utilizando-se as profundidades de $30 \mathrm{~cm}, 55 \mathrm{~cm}$ e $72 \mathrm{~cm}(\mathrm{Z})$ para o cálculo. A primeira e a segunda lâminas de irrigação foram aplicadas durante um período de 80 dias, enquanto que a terceira foi aplicada por 90 dias, ou seja, prevalecendo até o final do experimento.

A irrigação total necessária (ITN), em mm, foi calculada pela equação 6 (BERNARDO et al., 2005):

$$
\mathrm{ITN}=\mathrm{L} / \mathrm{Ea}
$$

sendo L a lâmina de irrigação (em mm) e Ea a eficiência de aplicação da irrigação, a qual foi utilizada $90 \%$.

O tempo (T) de irrigação, em horas, foi determinado pela equação 7 (BERNARDO et al., 2005):

$$
\mathrm{T}=\mathrm{ITN} / \mathrm{n} \times \mathrm{q}
$$

sendo ITN a irrigação total necessária (em mm), n o número de gotejadores por vaso e q a vazão do gotejador $\left(\mathrm{L} \cdot \mathrm{h}^{-1}\right)$.

\section{Características avaliadas e delineamento experimental}

$\mathrm{Na}$ superfície de quatro folhas totalmente expandidas na parte externa do terço superior da copa em uma única planta de cada clone, foram avaliadas a fotossíntese líquida, a condutância estomática, a transpiração e a eficiência do uso da água, estimada pelo quociente entre fotossíntese líquida e transpiração, com auxílio de um analisador a gas infravermelho portátil (Irga), modelo LCA-4, da ADC.

As medições foram realizadas ao longo de cinco horários, durante os dias 11 e 12 de outubro, às 8:00, 10:00, 12:00, 14:00 e 16:00 horas.

Para a determinação do potencial hídrico foliar, utilizou-se uma bomba de pressão (SHOLANDER et al., 1965), em uma folha totalmente expandida de três plantas de cada clone, localizadas na parte externa do terço superior do dossel. A avaliação foi feita em quatro horários durante o dia, às 4:30 (antemanhã), 8:00, 12:00 e 16:00 horas.

Os dados experimentais das trocas gasosas no horário das 10:00 horas e do potencial hídrico foliar antemanhã (às 4:30 horas) foram submetidos à análise de variância, e quando significativas, as médias foram comparadas pelo teste Tukey $5 \%$ de probabilidade, utilizando-se o software SAEG.

A escolha do horário deveu-se ao fato de que as plantas apresentam maior eficiência na fixação de carbono pela manhã, acentuando as respostas das mesmas nos manejos hídricos, e ao fato de o potencial hídrico foliar antemanhã ser considerado um indicativo do estado hídrico das plantas, apresentando a maior turgescência possível para uma dada condição hídrica encontrada no solo (LARCHER, 2004).

$\mathrm{O}$ experimento foi montado em esquema fatorial $3 \times 4$, sendo o fator manejo hídrico realizado em três níveis (irrigado, retomada da irrigação e déficit) e o fator clone em quatro níveis $(97,11,75$; e 84), num delineamento inteiramente casualizado. Foram utilizadas quatro repetições para as trocas gasosas e três para potencial hídrico foliar. 


\section{RESULTADOS E DISCUSSÃO}

\section{Caracterização do teor de água no substrato e chuva ocorrida durante o período experimental}

Observa-se na figura 2 que durante todo o período experimental foi monitorada a umidade do substrato, a fim de se determinar a condição hídrica prevalecente. Nota-se que a irrigação próxima à capacidade de campo foi interrompida no dia 30 de junho, a fim de submeter as plantas aos manejos hídricos, com retomada da irrigação no dia 15 de agosto, enquanto que no manejo de déficit a irrigação continuou suspensa até o final do experimento.

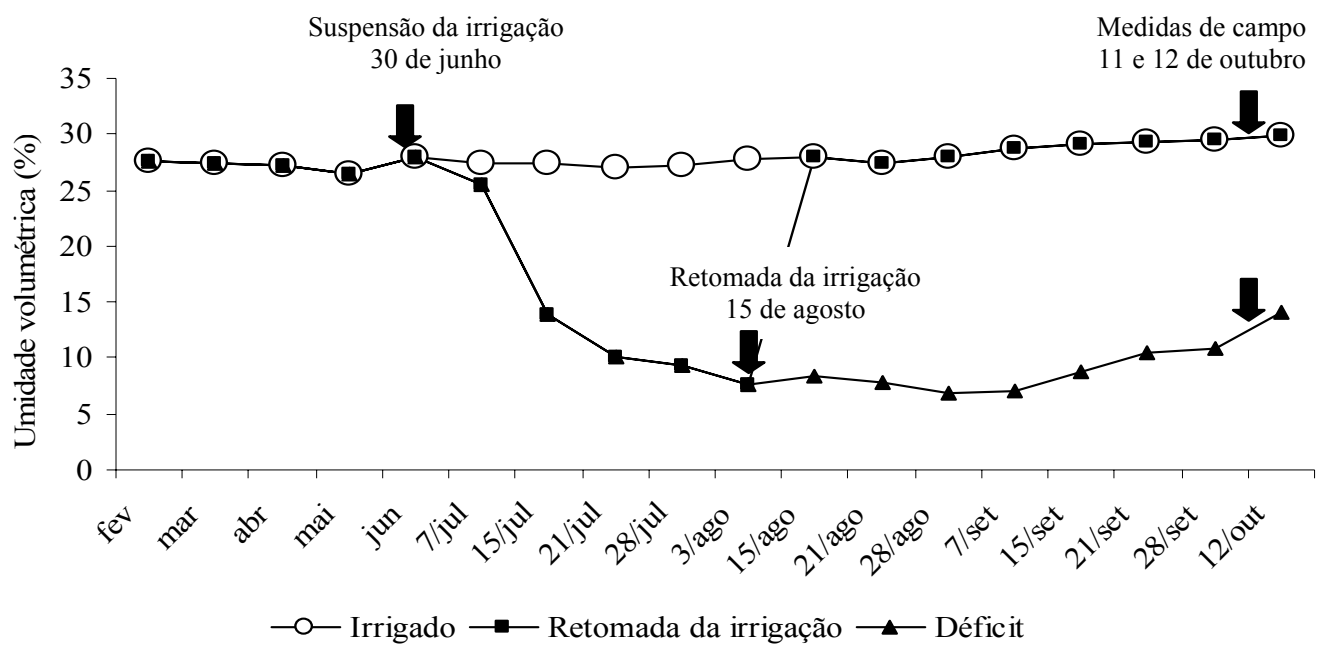

Figura 2. Variação da umidade do substrato nos respectivos manejos hídricos adotados nos vasos, medida a $30 \mathrm{~cm}$ de profundidade, durante o período experimental (Média de três vasos por manejo hídrico adotado).

Figure 2. Substrate water content variation for every water management adopted, measured at $30 \mathrm{~cm}$ of depth, during the experimental period (Average of three vases for handling adopted water).

Nota-se que a umidade do substrato no manejo hídrico irrigado ficou bem próxima à capacidade de campo durante todo o período experimental, com média de $27,9 \%$. Enquanto que, sob o manejo de déficit, a umidade atingiu valor médio de $9,2 \%$, logo após a estabilização da umidade na semana do dia 21 de julho. Observa-se também, no manejo de déficit, que a umidade do substrato apresentou um pequeno acréscimo em função das chuvas ocorridas, mas não comprometeu o manejo de déficit hídrico imposto às plantas (Figuras 2 e 3).

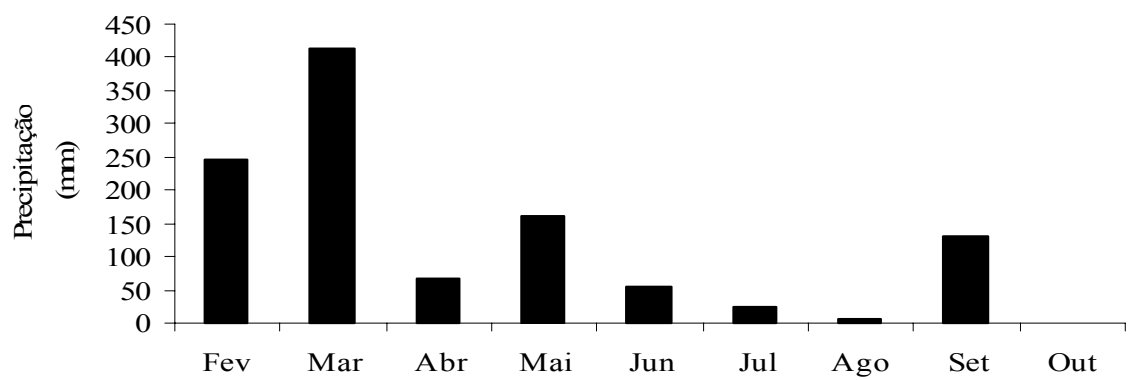

Figura 3. Valores mensais da precipitação, medidas na estação meteorológica automática durante o período experimental, entre 02 de fevereiro e 12 de outubro de 2005.

Figure 3. Monthly values of rainfall, measured in the automatic meteorological station during the experimental period, from February 02 to October 12, 2005. 
A figura 3 apresenta os valores mensais da precipitação pluviométrica, medidos na estação meteorológica automática, de dois de fevereiro a doze de outubro. Durante o período experimental, a precipitação total foi de $1.103 \mathrm{~mm}$, sendo a maior parte concentrada entre os meses de fevereiro e março (245 mm e 412,75 mm, respectivamente). O período experimental de maior escassez de chuvas ocorreu nos meses de julho, agosto e início do mês outubro.

\section{Avaliação das características ecofisiológicas}

A tabela 1 apresenta a avaliação do estudo das trocas gasosas e do potencial hídrico foliar de acordo com o teste de médias de Tukey para o manejo hídrico irrigado entre os clones. Observa-se que não houve diferença estatística para a taxa fotossintética, de transpiração e de eficiência no uso da água entre os clones, constatando-se semelhanças entre as médias dos resultados obtidos. Isso indica que os quatro clones estudados podem produzir bem em regiões que apresentam boa disponibilidade hídrica no solo ao longo do ano, o suficiente para conduzir os processos metabólicos primários da fotossíntese. Para a condutância estomática, o clone 11 diferiu dos demais, apresentando menor abertura dos estômatos. Esse mesmo clone apresentou o menor potencial hídrico foliar antemanhã, com -1,83 MPa, fato este que pode ter contribuído para a menor abertura estomática. Os clones 75 e 84 apresentaram os maiores teores de água nas folhas - ambos registraram média de -1,03 $\mathrm{MPa}$. O clone 97 apresentou valores da média intermediária, registrando $-1,13 \mathrm{MPa}$.

No manejo hídrico de retomada da irrigação, as variáveis ecofisiológicas transpiração e eficiência no uso da água não apresentaram diferença estatística entre os clones, mostrando similaridade entre as médias (Tabela 2).

Tabela 1. Fotossíntese líquida (A), condutância estomática (Gs), transpiração (E) e eficiência no uso da água (EUA), realizado às 10:00 horas, e potencial hídrico foliar antemanhã $(\psi)$ de quatro clones de eucalipto para o manejo hídrico irrigado.

Table 1. Liquid photosynthesis (A), stomatal conductance (Gs), transpiration (E) and water use efficiency (EUA) measured at 10:00 AM and leaf water potential ( $\psi \mathrm{h}$ ) of four eucalyptus clones for the water handling irrigate.

\begin{tabular}{|c|c|c|c|c|c|}
\hline Irrigado & $\begin{array}{c}\text { A } \\
\left(\mu \mathrm{mol} \cdot \mathrm{m}^{-2} \cdot \mathrm{s}^{-1}\right)\end{array}$ & 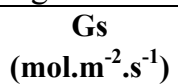 & $\begin{array}{c}\mathrm{E} \\
\left(\mathrm{mmol} \cdot \mathrm{m}^{-2} \cdot \mathrm{s}^{-1}\right)\end{array}$ & $\begin{array}{c}\text { EUA } \\
\left(\mu \text { mol.mmol }^{-1}\right)\end{array}$ & $\begin{array}{c}\psi_{\mathrm{h}} \\
(\mathrm{MPa})\end{array}$ \\
\hline Clone 97 & $12,02 \mathrm{a}$ & $0,305 \mathrm{a}$ & $7,64 \mathrm{a}$ & $1,58 \mathrm{a}$ & $-1,13 a b$ \\
\hline Clone 11 & $9,66 \mathrm{a}$ & $0,147 \mathrm{~b}$ & $6,57 \mathrm{a}$ & $1,49 \mathrm{a}$ & $-1,83 \mathrm{a}$ \\
\hline Clone 75 & $10,93 \mathrm{a}$ & $0,225 \mathrm{a}$ & $6,41 \mathrm{a}$ & $1,72 \mathrm{a}$ & $-1,03 b$ \\
\hline Clone 84 & $9,62 \mathrm{a}$ & $0,235 \mathrm{a}$ & $5,95 \mathrm{a}$ & $1,68 \mathrm{a}$ & $-1,03 b$ \\
\hline
\end{tabular}

*Médias seguidas das mesmas letras na coluna não diferem significativamente entre si pelo teste Tukey a $5 \%$ de probabilidade.

Para a fotossíntese, percebe-se diferença estatística entre as médias dos clones (Tabela 2). $\mathrm{O}$ clone 97 apresentou os maiores valores, com 10,95 $\mu \mathrm{mol} . \mathrm{m}^{-2} \cdot \mathrm{s}^{-1}$. Os clones 11 e 75 apresentaram valores intermediários, registrando, respectivamente, $8,56 \mathrm{e} 9,74 \mu \mathrm{mol} . \mathrm{m}^{-2} \cdot \mathrm{s}^{-1}$, enquanto o clone 84 apresentou o menor valor, com $7,42 \mu \mathrm{mol} . \mathrm{m}^{-2} . \mathrm{s}^{-1}$.

Tabela 2. Fotossíntese líquida (A), condutância estomática (Gs), transpiração (E) e eficiência no uso da água (EUA), realizado às 10:00 horas, e potencial hídrico foliar antemanhã $(\psi)$ de quatro clones de eucalipto para o manejo hídrico de retomada de irrigação.

Table 2. Liquid photosynthesis (A), stomatal conductance (Gs), transpiration (E) and water use efficiency (EUA) measured at 10:00 AM and leaf water potential ( $\psi \mathrm{h}$ ) of four eucalyptus clones with alternate irrigation regime.

\begin{tabular}{|c|c|c|c|c|c|}
\hline $\begin{array}{l}\text { Retomada da } \\
\text { irrigação }\end{array}$ & $\begin{array}{c}A \\
\left(\mu \mathrm{mol} . \mathrm{m}^{-2} \cdot \mathrm{s}^{-1}\right)\end{array}$ & $\begin{array}{c}\text { Gs } \\
\left(\mathrm{mol} \cdot \mathrm{m}^{-2} \cdot \mathrm{s}^{-1}\right)\end{array}$ & $\begin{array}{c}E \\
\left(\mathrm{mmol}^{\prime} \mathrm{m}^{-2} \cdot \mathrm{s}^{-1}\right)\end{array}$ & $\begin{array}{c}\text { EUA } \\
\left(\mu \mathrm{mol}^{\prime} \mathrm{mmol}^{-1}\right)\end{array}$ & $\begin{array}{c}\psi_{\mathrm{h}} \\
(\mathrm{MPa})\end{array}$ \\
\hline Clone 97 & $10,95 \mathrm{a}$ & $0,395 \mathrm{a}$ & $5,92 \mathrm{a}$ & $1,86 \mathrm{a}$ & $-1,16 a b$ \\
\hline Clone 11 & $8,56 \mathrm{ab}$ & $0,157 \mathrm{~b}$ & $5,84 \mathrm{a}$ & $1,51 \mathrm{a}$ & $-1,86 \mathrm{a}$ \\
\hline Clone 75 & $9,74 \mathrm{ab}$ & $0,242 \mathrm{~b}$ & $6,92 \mathrm{a}$ & $1,43 \mathrm{a}$ & $-1,06 \mathrm{~b}$ \\
\hline Clone 84 & $7,42 \mathrm{~b}$ & $0,115 \mathrm{~b}$ & $4,76 \mathrm{a}$ & $1,62 \mathrm{a}$ & $-1,00 b$ \\
\hline
\end{tabular}


Em termos de competição, o clone 97 pode ser aquele que, provavelmente, deve alcançar maior crescimento em regiões que apresentam variação na disponibilidade hídrica do solo ao longo do ano. Observase, também, para a condutância estomática diferença estatística entre as médias dos clones (Tabela 2). Verificase que o clone 97 apresentou a maior abertura estomática, quando comparado com os demais clones. Essa maior abertura dos estômatos encontrada para o clone 97 pode ter contribuído para sua maior assimilação do carbono, uma vez que é através dos estômatos que ocorre o influxo de $\mathrm{CO}_{2}$, necessário ao processo fotossintético e ao crescimento das plantas (BALDOCHI et al., 1991; LARCHER, 2004; TAIZ; ZEIGER, 2004).

Nota-se, na tabela 2, no manejo hídrico de retomada da irrigação, que o potencial hídrico foliar antemanhã apresentou teste de médias semelhante ao encontrado para as plantas mantidas irrigadas, com o clone 11 registrando os menores valores, seguido do clone 97, com valor intermediário, e posteriormente dos clones 75 e 84 , com as maiores médias.

$\mathrm{Na}$ tabela 3, é apresentado o estudo das variáveis ecofisiológicas entre os clones de eucalipto para o manejo hídrico de déficit. Nota-se que a única variável que não apresentou diferença estatística entre as médias dos clones foi a eficiência no uso da água, alcançando valores das médias equivalentes, possivelmente devido ao equilíbrio na variação entre a razão das taxas fotossintéticas e a transpiração ocorrida para cada um dos clones.

Tabela 3. Fotossíntese líquida (A), condutância estomática (Gs), transpiração (E) e eficiência no uso da água (EUA), realizado às 10:00 horas, e potencial hídrico foliar antemanhã $(\psi)$ de quatro clones de eucalipto para o manejo hídrico de déficit.

Table 3. Liquid photosynthesis (A), stomatal conductance (Gs), transpiration (E) and water use efficiency (EUA) measured at 10:00 AM and leaf water potential ( $\psi \mathrm{h}$ ) of four eucalyptus clones on water deficit.

\begin{tabular}{lccccc}
\hline Déficit & $\begin{array}{c}\mathbf{A} \\
\left(\boldsymbol{\mu} \mathbf{m o l} \cdot \mathbf{m}^{-\mathbf{2}} \cdot \mathbf{s}^{-\mathbf{1}}\right)\end{array}$ & $\begin{array}{c}\mathbf{G s} \\
\left(\mathbf{m o l} \cdot \mathbf{m}^{-\mathbf{2}} \cdot \mathbf{s}^{-\mathbf{1}}\right)\end{array}$ & $\begin{array}{c}\mathbf{E} \\
\left(\mathbf{m m o l} \cdot \mathbf{m}^{-\mathbf{2}} \cdot \mathbf{s}^{-\mathbf{1}}\right)\end{array}$ & $\begin{array}{c}\text { EUA } \\
\left(\boldsymbol{\mu m o l . m m o l} \mathbf{1}^{\mathbf{1}}\right)\end{array}$ & $\begin{array}{c}\boldsymbol{\psi}_{\mathbf{h}} \\
(\mathbf{M P a})\end{array}$ \\
\hline Clone 97 & $5,82 \mathrm{a}$ & $0,265 \mathrm{a}$ & $6,47 \mathrm{a}$ & $0,91 \mathrm{a}$ & $-2,60 \mathrm{~b}$ \\
Clone 11 & $1,19 \mathrm{~b}$ & $0,017 \mathrm{~b}$ & $1,40 \mathrm{~b}$ & $0,91 \mathrm{a}$ & $-2,80 \mathrm{~b}$ \\
Clone 75 & $7,18 \mathrm{a}$ & $0,232 \mathrm{a}$ & $5,90 \mathrm{a}$ & $1,20 \mathrm{a}$ & $-3,16 \mathrm{~b}$ \\
Clone 84 & $5,39 \mathrm{a}$ & $0,182 \mathrm{a}$ & $6,31 \mathrm{a}$ & $0,89 \mathrm{a}$ & $-4,70 \mathrm{a}$ \\
\hline
\end{tabular}

*Médias seguidas das mesmas letras na coluna não diferem significativamente entre si pelo teste Tukey a $5 \%$ de probabilidade.

A fotossíntese, a condutância estomática e a transpiração apresentaram resultados semelhantes na análise estatística encontrada para as médias entre os clones, com o clone 11 registrando os menores valores dessas três variáveis, mostrando ser o menos tolerante às condições de deficiência hídrica no solo, que pode afetar negativamente seu crescimento e estabelecimento no campo, quando comparado com os demais clones.

Para o potencial hídrico foliar antemanhã, também foi verificada diferença entre os clones no manejo hídrico de déficit (Tabela 3). Os clones 97, 11 e 75 apresentaram os maiores teor de água nas folhas, enquanto que no clone 84 esse teor apresentou-se reduzido.

$\mathrm{Na}$ tabela 4, são apresentadas as diferenças entre os três níveis de manejo hídrico em cada clone para cada variável ecofisiológica estudada. Observa-se, para os quatro clones, que houve diferença estatística na taxa fotossintética entre os manejos hídricos adotados. A retomada da irrigação, após o período de déficit hídrico, foi suficiente para que todos os clones recuperassem sua capacidade fotossintética, não mais existindo diferenças entre as plantas do manejo hídrico irrigado. Essa recuperação da fotossíntese após a retomada da irrigação contribuiu de forma significativa para incrementos no acúmulo de matéria seca total da grande maioria dos clones estudados (TATAGIBA et al., 2007).

Nota-se, ainda, que, sob déficit, houve queda nas taxas fotossintéticas em cada clone, observada pela diferença encontrada entre as plantas mantidas irrigadas. Em condições de seca, a fotossíntese normalmente diminui, e isso pode ser devido ao fechamento parcial dos estômatos e, também, pela interferência no processo fotossintético. Para a condutância estomática e a transpiração, foram encontrados resultados similares no teste de média Tukey entre os manejos hídricos de cada clone. Com exceção do clone 11, não foi encontrada diferença estatística entre os três manejos hídricos adotados para 
a condutância estomática, ao contrário do que se esperava. Para a transpiração, a diferença esperada entre os manejos hídricos irrigado e de déficit também não foi encontrada.

Tabela 4. Fotossíntese líquida (A), condutância estomática (Gs), transpiração (E) e eficiência no uso da água (EUA), realizado às 10:00 horas, e potencial hídrico foliar antemanhã $(\psi)$ de quatro clones de eucalipto nos manejos hídricos irrigado, retomada da irrigação e déficit.

Table 4. Liquid photosynthesis (A), stomatal conductance (Gs), transpiration (E) and water use efficiency (EUA) measured at 10:00 AM and leaf water potential ( $\psi \mathrm{h}$ ) of four eucalyptus clones on different water regimes.

\begin{tabular}{|c|c|c|c|c|c|}
\hline $\begin{array}{l}\text { Manejos hídricos em } \\
\text { cada clone }\end{array}$ & $\begin{array}{c}\text { A } \\
\left(\mu \mathrm{mol} . \mathrm{m}^{-2} \cdot \mathrm{s}^{-1}\right)\end{array}$ & $\begin{array}{c}\text { Gs } \\
\left(\mathrm{mol}^{-m^{-2}} \cdot \mathrm{s}^{-1}\right)\end{array}$ & $\begin{array}{c}\mathbf{E} \\
\left(\mathrm{mmol} \cdot \mathrm{m}^{-2} \cdot \mathrm{s}^{-1}\right)\end{array}$ & $\begin{array}{c}\text { EUA } \\
\left(\mu \text { mol.mmol }^{-1}\right)\end{array}$ & $\begin{array}{c}\psi_{\mathrm{h}} \\
(\mathrm{MPa})\end{array}$ \\
\hline \multicolumn{6}{|l|}{ Clone 97} \\
\hline Irrigado & $12,02 \mathrm{a}$ & $0,305 \mathrm{a}$ & $7,64 \mathrm{a}$ & $1,58 \mathrm{a}$ & $-1,13 b$ \\
\hline Retomada irrigação & $10,95 \mathrm{a}$ & $0,395 \mathrm{a}$ & $5,92 \mathrm{a}$ & $1,86 \mathrm{a}$ & $-1,16 b$ \\
\hline Déficit & $5,82 \mathrm{~b}$ & $0,265 \mathrm{a}$ & $6,47 \mathrm{a}$ & $0,91 \mathrm{~b}$ & $-2,60 a$ \\
\hline \multicolumn{6}{|l|}{ Clone 11} \\
\hline Irrigado & $9,66 \mathrm{a}$ & $0,147 \mathrm{a}$ & $6,57 \mathrm{a}$ & $1,49 \mathrm{a}$ & $-1,83 b$ \\
\hline Retomada irrigação & $8,56 \mathrm{a}$ & $0,157 \mathrm{a}$ & $5,84 \mathrm{a}$ & $1,50 \mathrm{a}$ & $-1,86 b$ \\
\hline Déficit & $1,19 \mathrm{~b}$ & $0,017 \mathrm{~b}$ & $1,40 \mathrm{~b}$ & $0,91 \mathrm{~b}$ & $-2,80 \mathrm{a}$ \\
\hline \multicolumn{6}{|l|}{ Clone 75} \\
\hline Irrigado & $10,93 \mathrm{a}$ & $0,242 \mathrm{a}$ & $6,41 \mathrm{a}$ & $1,72 \mathrm{a}$ & $-1,03 b$ \\
\hline Retomada irrigação & $9,74 \mathrm{a}$ & $0,232 \mathrm{a}$ & $6,92 \mathrm{a}$ & $1,43 \mathrm{a}$ & $-1,06 \mathrm{~b}$ \\
\hline Déficit & $7,18 \mathrm{~b}$ & $0,225 \mathrm{a}$ & $5,90 \mathrm{a}$ & $1,20 \mathrm{a}$ & $-3,16 a$ \\
\hline \multicolumn{6}{|l|}{ Clone 84} \\
\hline Irrigado & $9,62 \mathrm{a}$ & $0,235 \mathrm{a}$ & $5,95 \mathrm{a}$ & $1,68 \mathrm{a}$ & $-1,03 b$ \\
\hline Retomada irrigação & $7,42 \mathrm{ab}$ & $0,115 \mathrm{a}$ & $4,76 \mathrm{a}$ & $1,62 \mathrm{a}$ & $-1,00 \mathrm{~b}$ \\
\hline Déficit & $5,39 \mathrm{~b}$ & $0,182 \mathrm{a}$ & $6,31 \mathrm{a}$ & $0,89 \mathrm{~b}$ & $-4,70 \mathrm{a}$ \\
\hline
\end{tabular}

Médias seguidas das mesmas letras na coluna dentro de cada clone não diferem significativamente entre si pelo teste Tukey a 5\% de probabilidade.

A eficiência no uso da água apresentou diferença estatística entre os manejos hídricos adotados para os clones 97,11 e 84 . No manejo de déficit, esses clones registraram os menores valores de eficiência no uso da água, quando comparados com as plantas mantidas irrigadas. Esse decréscimo da eficiência no uso da água apresentado pelos clones submetidos ao déficit hídrico pode ter ocorrido devido à baixa disponibilidade de água encontrada no substrato. Nota-se que no manejo irrigado e de retomada de irrigação não foi encontrada diferença estatística, constatando-se os maiores valores, possivelmente pela maior disponibilidade de água. Resultados semelhantes foram encontrados por Pereira et al. (1986) em um plantio de E. globulus, observando maiores valores da eficiência instantânea no uso da água durante a época de maior suprimento hídrico no solo, enquanto que Mielke (1997) verificou uma tendência de aumento na eficiência instantânea no uso da água à medida que diminuía a disponibilidade hídrica do solo em um plantio de E. grandis. O clone 75 apresentou eficiência no uso da água semelhante entre os três manejos hídricos adotados, podendo-se pressupor que esse clone possa apresentar estratégia eficiente no uso da água durante um período determinado de seca no solo.

O potencial hídrico foliar antemanhã no manejo hídrico de déficit apresentou diferença estatística em relação aos outros manejos adotados. Os clones 97,75 e 84 apresentaram os menores valores. No clone 11, os manejos hídricos não diferiram estatisticamente (Tabela 4). Percebe-se, também, que as plantas anteriormente mantidas no manejo de retomada da irrigação recuperaram sua turgescência, não diferindo das plantas mantidas no manejo hídrico irrigado.

Variação diurna das trocas gasosas, do potencial hídrico foliar e da condição climática do ambiente

Percebe-se, na figura 4, as taxas fotossintéticas encontradas para cada clone de eucalipto, nos três manejos hídricos adotados, nos horários das medições realizadas ao longo do dia. Nota-se que, no manejo hídrico de déficit, os quatro clones apresentaram as menores taxas fotossintéticas. Verifica-se também, no manejo hídrico irrigado e de retomada da irrigação, que a variação entre os valores ao longo de todo o dia foi menor do que na encontrada entre as plantas mantidas irrigadas e as submetidas ao déficit hídrico, mostrando a recuperação da taxa fotossintética das plantas após a retomada da irrigação. É importante 
observar que o manejo hídrico de déficit afetou a assimilação fotossintética do $\mathrm{CO}_{2}$, promovendo queda na taxa fotossintética líquida, a partir das 10:00 horas da manhã, sendo o clone 11 o mais afetado. Observa-se, também, que o clone 84 apresentou a maior variação das taxas fotossintéticas durante os horários ao longo do dia entre os manejos hídrico irrigado e de retomada da irrigação.
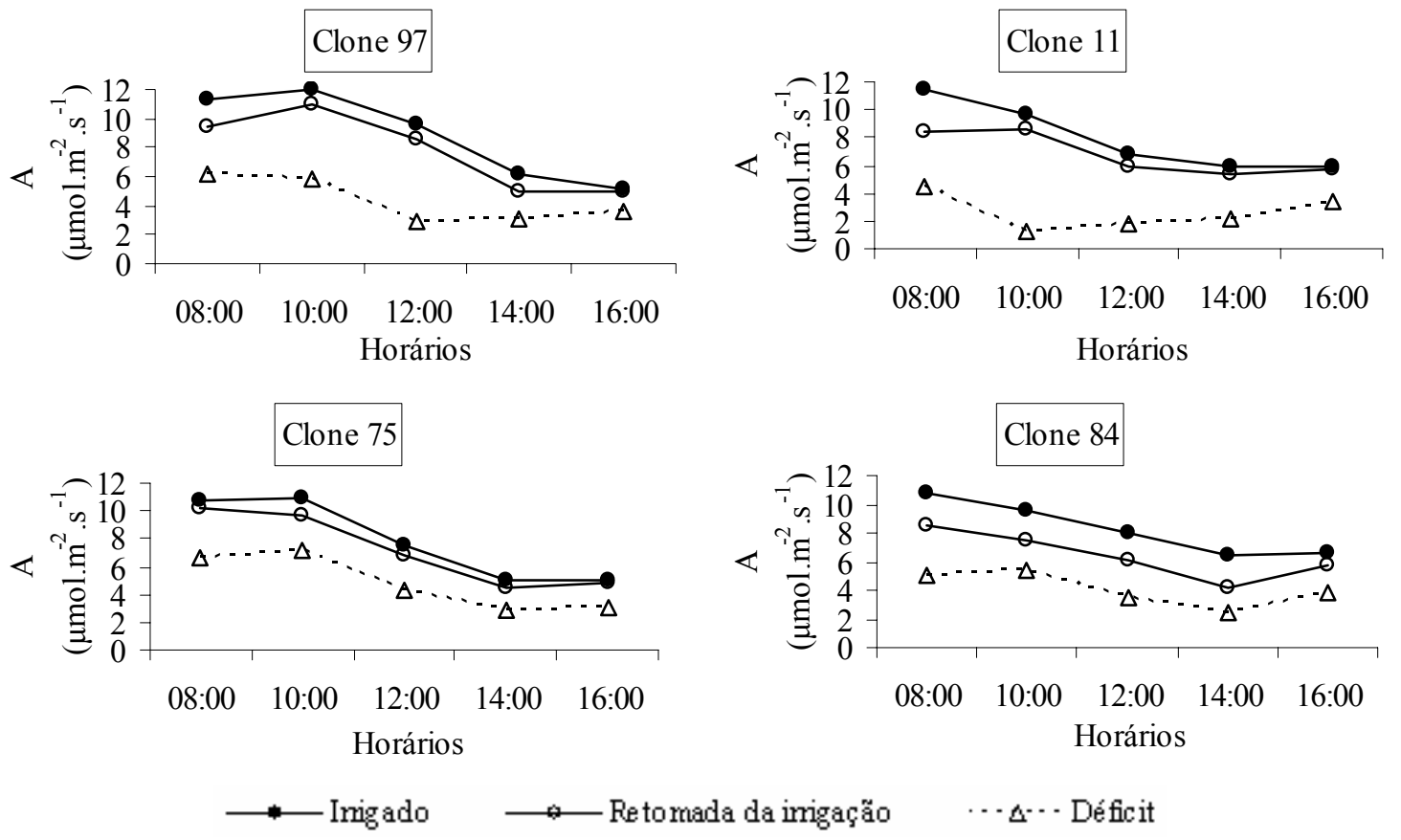

Figura 4. Fotossíntese líquida (A) ao longo do dia 12 de outubro de quatro clones de eucalipto, crescendo em vasos sob diferentes manejos hídricos.

Figure 4. Liquid photosynthesis (A) along October 12th of four eucalyptus clones, growing in vases under different water regimes.

O maior valor de fotossíntese foi encontrado no manejo hídrico irrigado, com $12,00 \mu \mathrm{mol} \cdot \mathrm{m}^{-2} . \mathrm{s}^{-1}$, verificado para o clone 97, às 10:00 horas, enquanto o menor valor foi verificado para o clone 11 , no manejo hídrico de déficit, no mesmo horário, com $1,19 \mu \mathrm{mol} \cdot \mathrm{m}^{-2} \cdot \mathrm{s}^{-1}$. Mielke (1997) detectou quedas nas taxas fotossintéticas de um plantio de clones Eucalyptus grandis, quando submetidos a déficit hídrico moderado, o qual esteve relacionado com a variação sazonal das taxas de precipitação pluviométrica.

A figura 5 apresenta os valores da condutância estomática de cada clone ao longo do dia nos três manejos hídricos adotados. Nota-se que a variação da condutância estomática no manejo de déficit foi maior nos clones 97 e 11 ao longo de todos os horários, em relação aos manejos mantidos com a umidade próxima à capacidade de campo, enquanto que os clones 75 e 84 , nos mesmos manejos, apresentaram menor variação. $\mathrm{O}$ clone 11 foi o que apresentou, sob déficit, a menor condutância estomática ao longo dos horários durante o dia.

Essa diferença da condutância estomática encontrada entre os manejos hídricos ocorreu devido ao estresse hídrico severo imposto pela deficiência hídrica, a partir da baixa umidade encontrada no substrato, levando alguns clones ao fechamento parcial dos estômatos logo nas primeiras horas da manhã, fato este que pode ter provocado quedas das taxas fotossintéticas dos clones.

À medida que a deficiência hídrica é imposta, ocorre redução na condutância estomática. Nesse sentido, a interação da deficiência hídrica com outros fatores do ambiente, como altas intensidades luminosas, déficit de pressão de vapor, temperaturas elevadas e baixas umidades do ar, pode, também, contribuir para o fechamento parcial dos estômatos. Dessa forma, é importante observar que as variáveis ecofisiológicas estudadas acompanharam a demanda evaporativa da atmosfera. $\mathrm{O}$ aumento do déficit pressão de vapor, da radiação solar incidente, da temperatura do ar e o abaixamento da umidade relativa após o período da manhã, favoreceu a redução dos valores das trocas gasosas (Figura 6). A demanda 
evaporativa da atmosfera tem indicado ser um efeito altamente significativo sobre a condutância estomática em plantas lenhosas (BALDOCHI et al., 1991).
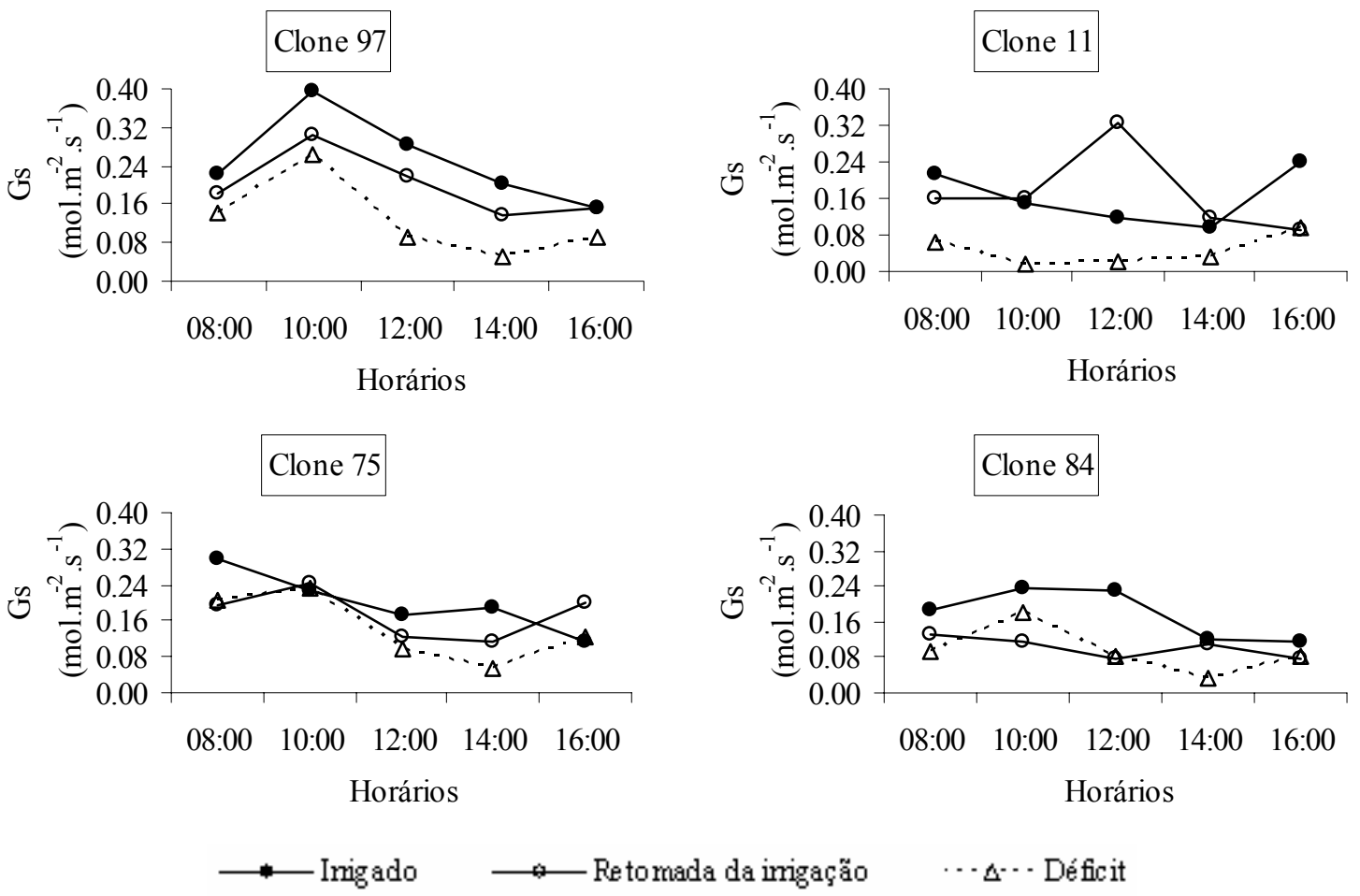

Figura 5. Condutância estomática (Gs) ao longo do dia 12 de outubro de quatro clones de eucalipto, crescendo em vasos sob diferentes manejos hídricos.

Figure 5. Stomatal conductance (Gs) along October 12th of four eucalyptus clones, growing in vases under different water regimes.
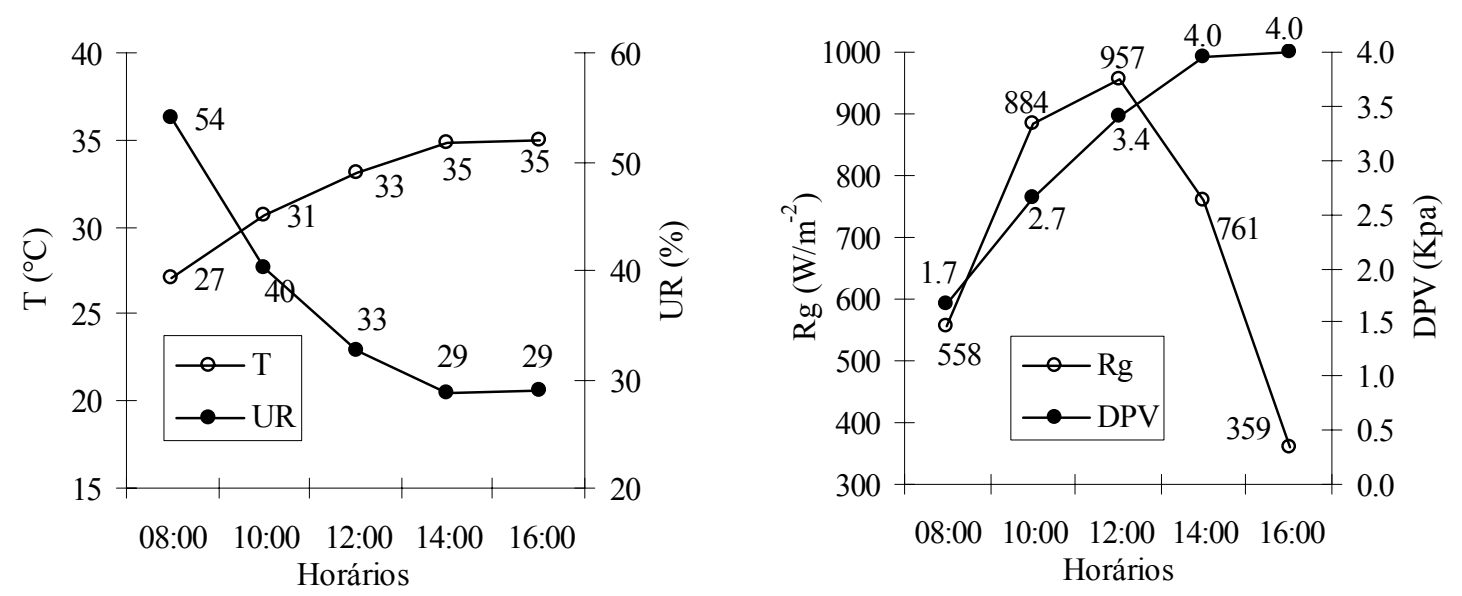

Figura 6. Temperatura média do ar (T), umidade relativa média (UR), Radiação solar global (Rg) e déficit pressão de vapor médio (DPV) ao longo do dia 12 de outubro.

Figure 6. Average temperature of the air (T), average relative humidity (UR), deficit pressure of medium steam (DPV) and incident solar radiation (Rg) along October, 12th. 
Observa-se, para a maioria dos clones, que os menores valores de condutância estomática foram encontrados no período da tarde, quando as condições do ambiente eram mais estressantes para as plantas nos três manejos hídricos. Por outro lado, no período da manhã, ocorreu maior abertura estomática, já que os efeitos das variáveis climáticas eram menos estressantes. Como aconteceu para a condutância estomática, o manejo hídrico de déficit contribuiu para a redução da transpiração nos clones, em comparação aos manejos irrigado e de retomada da irrigação, principalmente no período da tarde, quando as condições climáticas eram mais estressantes para as plantas (Figura 7). Verifica-se que a deficiência hídrica imposta pelo manejo de déficit afetou mais intensamente a transpiração no clone 11 , contribuindo para a redução da perda de água na forma de vapor. A redução da transpiração em conseqüência do fechamento estomático é uma das primeiras respostas no sentido de reduzir o uso de água pelas plantas sob deficiência hídrica (LARCHER, 2004; TAIZ; ZEIGER, 2004). Notam-se, também, alternâncias nos maiores valores de transpiração ao longo do dia nos manejos irrigado e de retomada de irrigação, já que a umidade encontrada no substrato era semelhante.
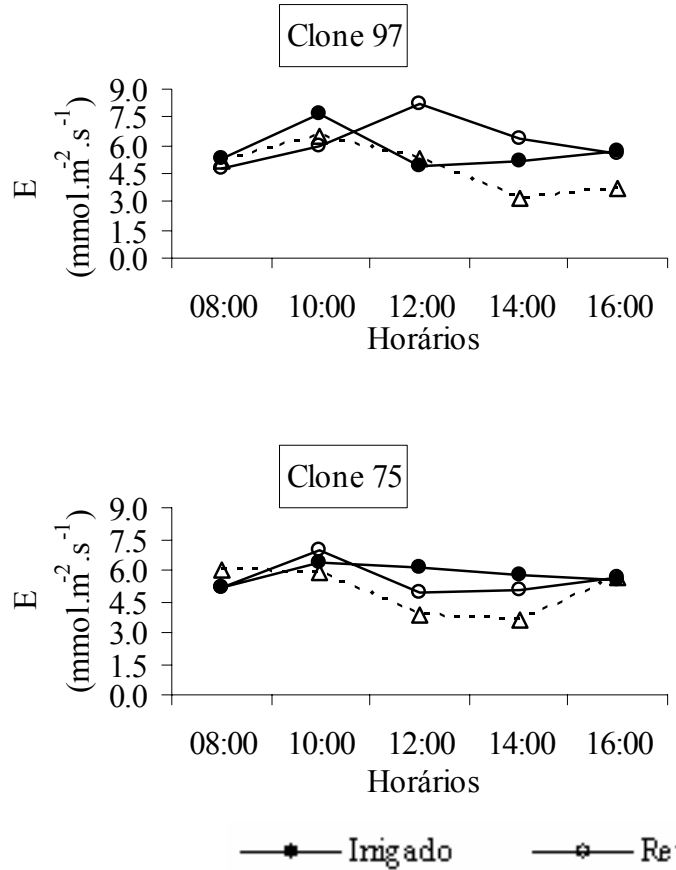

Figura 7. Transpiração (E) ao longo do dia 12 de outubro de quatro clones de eucalipto, crescendo em vasos sob diferentes manejos hídricos.

Figure 7. Transpiration along October 12th of four eucalyptus clones, growing in vases under different water regimes.

A eficiência no uso de água sofreu variação durante o curso diário nos manejos hídricos em cada clone (Figura 8). No manejo de déficit, a eficiência no uso da água foi reduzida nos quatro clones, quando comparado com os demais manejos, sendo o efeito mais negativo no período da tarde. As máximas eficiências registradas para os quatro clones, nos três manejos hídricos ocorreram durante o período da manhã. Nota-se que os valores de eficiência no uso da água entre os clones nos três manejos hídricos foram semelhantes durante o dia.

$\mathrm{Na}$ natureza, a eficiência no uso da água é influenciada pelas condições climáticas. Geralmente, a eficiência no uso da água alcança os maiores valores durante as primeiras horas do período da manhã, quando o ar contém grande quantidade de vapor d'água e há radiação suficiente para atingir a capacidade fotossintética. Nas horas seguintes, a eficiência no uso da água declina, quando a folha é fortemente aquecida, a umidade do ar diminui e as correntes turbulentas do ar promovem a evaporação (LARCHER, 2004).

FLORESTA, Curitiba, PR, v. 38, n. 2, abr./jun. 2008. 

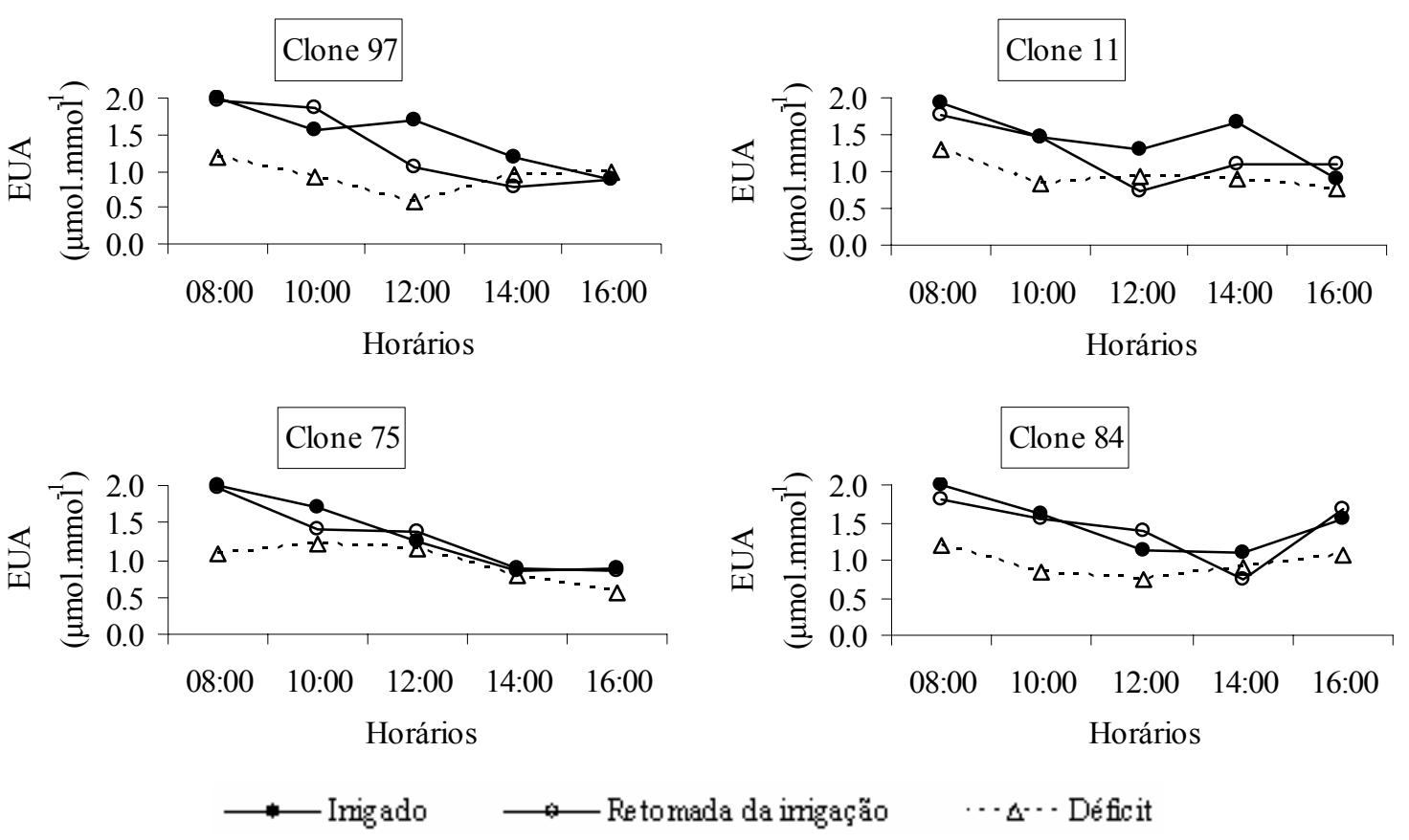

$\cdots \cdot-$ Déficit

Figura 8. Eficiência no uso da água (EUA) ao longo do dia 12 de outubro de quatro clones de eucalipto, crescendo em vasos sob diferentes manejos hídricos.

Figure 8. Efficiency in the use of the water (EUA) along October 12th of four eucalyptus clones, growing in vases under different water regimes.

Na figura 9, observa-se o comportamento do potencial hídrico foliar ao longo das medições realizadas durante o dia entre os três manejos hídricos para cada clone. Observa-se que, sob o manejo hídrico de déficit, os clones apresentaram menores valores de potencial hídrico foliar ao longo do dia. Nota-se, também, que, após a retomada da irrigação, os quatro clones recuperaram a turgescência, com valores semelhantes aos encontrados no manejo hídrico irrigado. Mielke (1997), observando o potencial hídrico antemanhã e o potencial hídrico foliar ao meio dia de plantas adultas de Eucalyptus grandis, relatou que os valores acompanharam as variações observadas no teor de umidade do solo. Considerável variação do potencial hídrico foliar foi encontrada, nos três manejos hídricos, durante os horários das medições realizadas ao longo do dia. A ocorrência dessa variação durante o dia se deu, provavelmente, em função da alta demanda evaporativa da atmosfera encontrada nos horários mais quentes do dia. O clone que apresentou maior variação do potencial hídrico foliar entre os manejos hídricos de déficit e irrigado foi o 75. Nos clones mantidos sob o manejo de déficit, o valor mais alto de potencial hídrico foliar encontrado no antemanhã foi de $-4,73 \mathrm{MPa}$, para o clone 84 , e o mais baixo de -20,0 MPa, para o clone 75 , às 8:00 horas.

\section{CONCLUSÕES}

Os clones estudados apresentaram diferentes respostas aos manejos hídricos com disponibilidade diferenciada de água no substrato. O clone 11 apresentou a menor taxa fotossintética sob o manejo de déficit hídrico quando comparado com os demais clones, mostrando obter estratégia ineficiente no crescimento e posterior estabelecimento no campo. De modo geral, esse mesmo clone apresentou a menor condutância estomática e transpiração, indicando menor consumo de água.

Os maiores valores da taxa fotossintética líquida nas plantas do clone 97 e, posteriormente, a encontrada no clone 75 no manejo hídrico de retomada da irrigação indicam rápida recuperação do crescimento após um período de déficit hídrico no solo. Por sua vez, os maiores valores de fotossíntese, 
encontrados no manejo hídrico de déficit, para os clones 97 e 75 , evidenciaram que são os mais indicados para plantio em áreas com elevada deficiência hídrica no solo, podendo apresentar maior crescimento.

A eficiência no uso da água demonstrou ser uma estratégia ineficiente na seleção de clones para ambientes com diferenciada disponibilidade hídrica no solo, enquanto que a taxa fotossintética e o potencial hídrico foliar parecem ser as variáveis estudadas mais indicadas para se avaliar a resistência dos clones ao déficit hídrico.
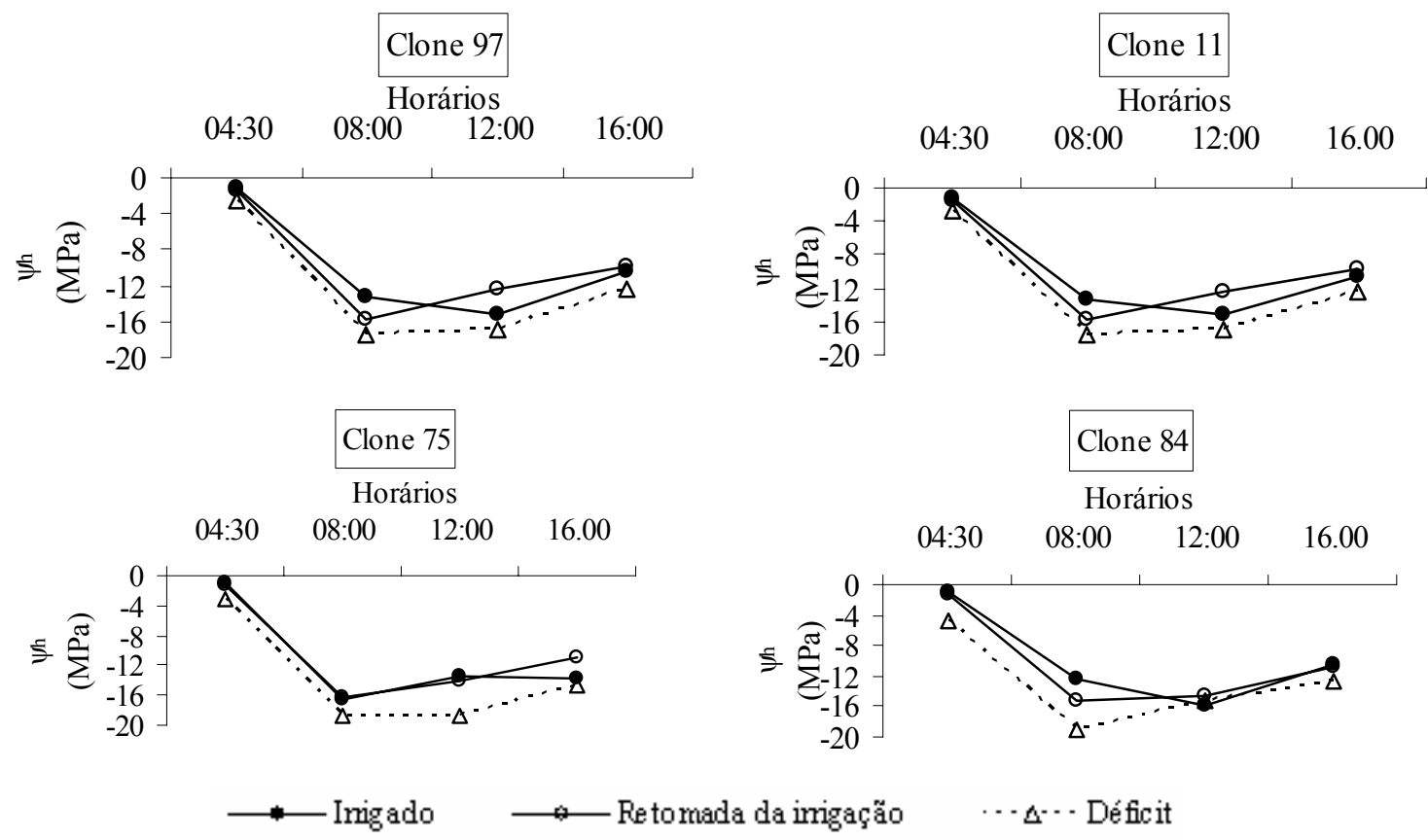

Figura 9. Potencial hídrico foliar $(\psi \mathrm{h})$ ao longo do dia 12 de outubro de quatro clones de eucalipto, crescendo em vasos sob diferentes manejos hídricos.

Figure 9. Leaf water potential $(\psi \mathrm{h})$ along October 12th of four eucalyptus clones, growing in vases under different water regimes.

\section{REFERÊNCIAS}

BALDOCHI, D. D.; LUXMOORE, R. J.; HATFIELD, J. L. Discerning the Forest from the trees: an essay on scaling canopy stomatal conductance. Agricultural and Forest Meteorology, Amsterdam, v. 54, p. 197-226, 1991.

BERNARDO, S.; SOARES, A. A.; MANTOVANI, E. C. Manual de irrigação. 7. ed. Viçosa, MG: UFV, 2005. $611 \mathrm{p}$.

CHAVES, J. H.; REIS, G. G.; REIS, M. G. F.; NEVES, J. C. L.; PEZZOPANE, J. E. M.; POLLI, H. Q. Early selection of eucalypt clones to be planted in environments with varying soil water availability: water relations of plants in small size plastic tubes. Revista Árvore, Viçosa, MG, v. 28, n. 3, p. 333-341, 2004.

CENTURION, J. F.; ANDREOLI, I. Regime hídrico de alguns solos de Jaboticabal. Revista Brasileira de Ciência do Solo, Viçosa, MG, v. 24, p. 701-709, 2000.

EMBRAPA - Empresa Brasileira de Pesquisas Agropecuárias. Serviço Nacional de Levantamento e Conservação de Solos. Manual de métodos de análise de solos. 2. ed. Rio de Janeiro, 1997. 212 p. 
FAÇANHA, J. G. V. Aspectos fisiológicos do crescimento de Eucalyptus spp. Submetidos à deficiência hídrica. 47 f. Dissertação (Mestrado em Fisiologia Vegetal) - Universidade Federal de Viçosa, Viçosa, MG, 1983.

FRAMPTON JR, L. J.; FOSTER, G. S. Field testing vegetative propagules. In: AHUJA, M. R.; LIBBY, W. J. Clonal foresty I: genetics and biotechnology, Berlin: Spring Verlag, 1993 p. 110-134.

GONÇALVES, M. R.; PASSOS, C. A. M. Crescimento de cinco espécies de eucalipto submetidas a déficit hídrico em dois níveis de fósforo. Ciência Florestal, Santa Maria, v. 10, n.2 , p. 145-161, 2000.

LARCHER, W. Ecofiosiologia vegetal. São Carlos: Rima, 2004. 531 p.

LI, C. Variations of seedlings traits of Eucalyptus microtheca origins in different watering regimes. Silvae Genetica, Grosshansdorf, v. 47,n. 2-3, 1998.

LIMA, W. P.; JARVIS, P.; RHIZOPOULOU, S. Stomatal responses of Eucalyptus species to elevated CO2 concentration and drought stress. Scientia Agricola, Piracicaba, v. 60, n. 2, p. 231-238, 2003.

MIELKE, M. S. Regulação fisiológica e ambiental das trocas gasosas num plantio clonal de híbridos de Eucalyptus grandis Hill ex-Maiden. 92 f. Tese (Doutorado em Fisiologia Vegetal) - Universidade Federal de Viçosa, Viçosa, MG, 1997.

PEREIRA, J. S.; TENHUNEN, J. D.; LANGE,O. L.; BEYSCHLAG, W.; MEYER, A.; DAVID, M. M. Seasonal and diurnal patterns in leaf gas Exchange of Eucalyptus globulus trees growing in Portugal. Canadian Journal of Forest Research, Ottawa, v. 16, p. 177-184, 1986.

PEREIRA, A. R.; ANGELOCCI, L. R.; SENTELHAS, P. C. Agrometeorologia fundamentos e aplicações. Guaíba: Agropecuária, 2002. 478 p.

SHOLANDER, P. F.; HAMMEL, H. T.; BRADSTREET, E. D.; HEMMINGSEN, E. A. Sap pressure in vascular plants. Science, Cambridge, v. 148, p.339-346, 1965.

SILVEIRA, R. L. V. A.; HIGASHI, E. N.; SGARBI, F.; MUNIZ, M. R. A. Seja doutor de seu eucalipto. Arquivo do Agrônomo, São Paulo, n. 12, p. 1-32, 2001.

SOUSA, M. B. A.; MANTOVANI, E. C.; SOUZA, L. O.; BUFON, V. N.; BONOMO, R. Avaliação de irrigação em propriedades de café conilon no norte do Espírito Santo. In: Irrigação do cafeeiro: informações técnicas e coletâneas de trabalhos.Viçosa, MG: Associação dos Engenheiros Agrícolas de Minas Gerais:UFV. DEA, 2003. 260 p.

TAIZ, L.; ZEIGER E. Fisiologia vegetal. 3. ed. Porto Alegre: Artemed, 2004. 719 p.

TATAGIBA, S. D.; PEZZOPANE, J. E. M.; REIS, E. F. Avaliação do crescimento e produção de clones de Eucalyptus submetidos a diferentes manejos de irrigação. Cerne. Lavras, v. 13, n. 1, p. 1-9, 2007.

VAN GENUCHTEN, M. T. A closed-form for predicting the hydraulic conductivity of unsaturated soils. Soil Science Society of American Journal, Madison, v. 41, p. 892-898, 1980. 